\title{
Pathological switching between languages after frontal lesions in a bilingual patient
}

\author{
Franco Fabbro, Miran Skrap, Salvatore Aglioti
}

\begin{abstract}
Cerebral lesions may alter the capability of bilingual subjects to separate their languages and use each language in appropriate contexts. Patients who show pathological mixing intermingle different languages within a single utterance. By contrast, patients affected by pathological switching alternate their languages across different utterances (a self contained segment of speech that stands on its own and conveys its own independent meaning). Cases of pathological mixing have been reported after lesions to the left temporoparietal lobe. By contrast, information on the neural loci involved in pathological switching is scarce. In this paper a description is given for the first time of a patient with a lesion to the left anterior cingulate and to the frontal lobe-also marginally involving the right anterior cingulate area-who presented with pathological switching between languages in the absence of any other linguistic impairment. Thus, unlike pathological mixing that typically occurs in bilingual aphasia, pathological switching may be independent of language mechanisms. (F Neurol Neurosurg Psychiatry 2000;68:650-652)
\end{abstract}

Neurolinguistic Unit, Istituto Scientifico "E Medea", 23842 Bosisio Parini (LC), Italy and University of Udine, Italy

F Fabbro

Department of Neurosurgery, General Hospital, Udine, Italy M Skrap

Department of Psychology, University "La Sapienza", and IRCCS S Lucia, Rome, Italy

S Aglioti

Correspondence to: Dr Franco Fabbro fabbro@bp.Lnf.it

Received 19 July 1999 and in revised form

13 December 1999

Accepted 5 January 2000
Keywords: bilingual brain; pathological switching between languages; frontal lobes

Many neurologists have supported the hypothesis whereby in bilingual subjects there is a centre responsible for the ability to use one language instead of another. Classic studies hypothesised that this centre is located in the posterior boundary of the Sylvian fissure and in the neighbouring parietal region involving the supramarginal gyrus. ${ }^{12}$ According to these reports, the alteration of the mechanism that allows bilingual people to use a given language at will causes a patient either to speak only one language or to alternate between languages without control. Subsequent studies, however, have made a cogent distinction between pathological switching and pathological mixing phenomena. ${ }^{3}$ In pathological mixing multilingual patients mix two or more languages within a single utterance, whereas in pathological switching patients alternate utterances in one language to utterances in another, even when the interlocutor cannot understand one of the two languages. Numerous studies have established that pathological mixing is mainly due to lesions in the parietotemporal structures of the left hemisphere, whereas the nervous structures responsible for switching between languages have not yet been clearly described. ${ }^{56}$ The study of the bilingual patient reported here has allowed us to establish - for the first timethe role of anterior brain structures in the switching mechanism in multilingual subjects.

\section{Method}

CASE REPORT

The patient was a right handed, 56 year old native Friulian (language 1 (L1)) man with Italian as his second language (L2). He completed his education in Italian (13 years) and over the past 20 years he had worked as a building surveyor and financial consultant in his own company. In the spring of 1994 the patient noticed that when walking or driving he tended to lean to the right and that his psychological attitude had changed, too, because the anxiety and the phobias he had had all his life had become less severe.

In July 1994, while going on holiday, he succeeded in taking a flight for the first time in his life because his phobia of flying had disappeared. During that holiday he noticed that he often spoke in Friulian with a close friend whom he had known for more than 20 years and who did not understand that language. The patient could not control this compulsive tendency. $\mathrm{He}$ was conscious, however, of the social inadequacy of his linguistic behaviour and after producing sentences in Friulian, he immediately translated them into Italian for his friend. Because his problems with walking and driving became increasingly severe, in July 1994 he had an MRI disclosing a tumour in the white matter in the left frontal lobe, $6 \mathrm{~cm}$ in diameter, provoking a slight shift of the midline. On 30 September 1994, the patient underwent a computer assisted stereotactic volumetric resection. In March 1995 the patient had an MRI disclosing an extension of the tumour now marginally involving the right cingulate area as well (figure). A second operation using the same stereotactic method was performed. After that, the patient exhibited a right hemiplegia, and for a few days he was drowsy. Subsequently, he recovered slightly but 

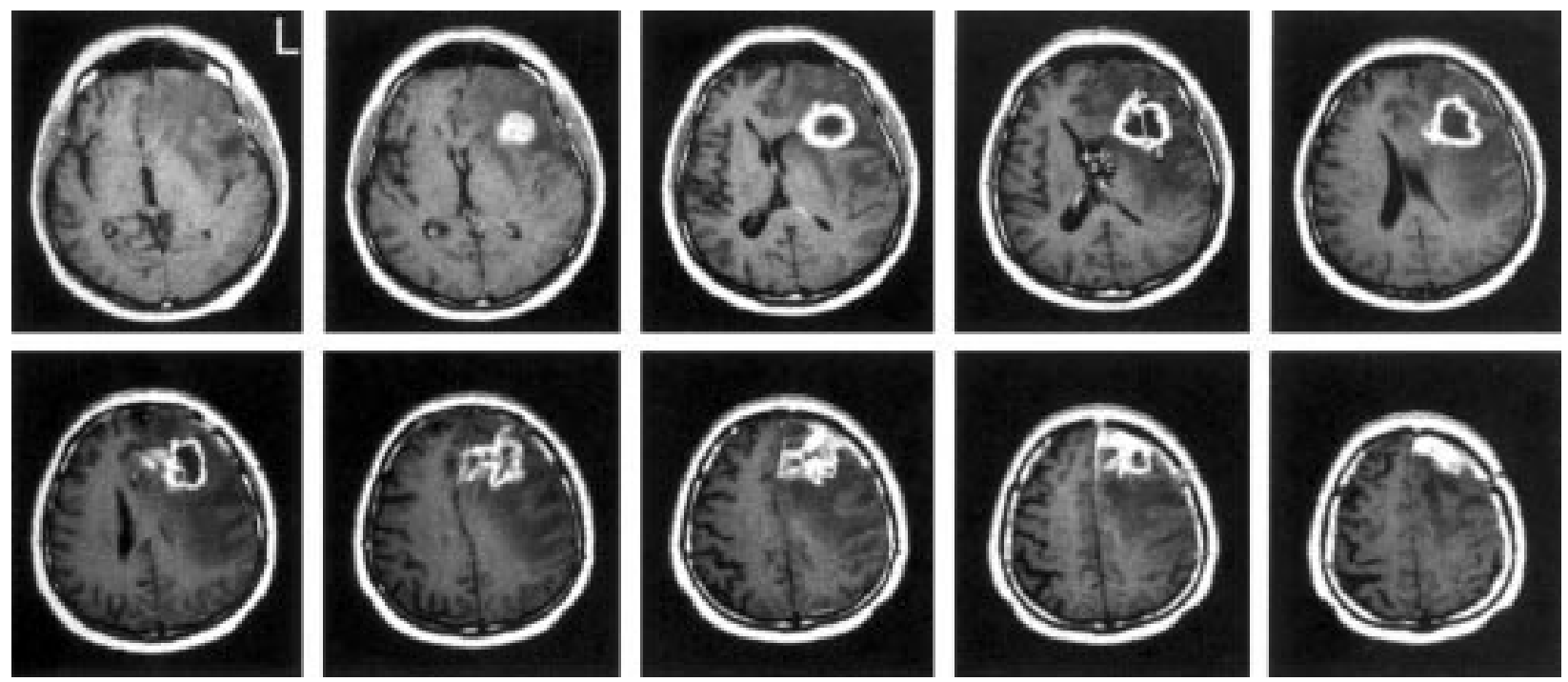

Figure 1 Selected axial, T1 weighted, and contrast enhanced MRI showing the extent of the patient's lesion. On the left side the lesion affects the white matter underlying the inferior, middle, and superior frontal gyri, the anterior callosal structures, the anterior arm of the internal capsule, the striatum, the premotor area, the frontal eye field, and the cingulate gyrus. The right cingulate gyrus is also slightly involved. Perilesional oedema affected Brodmann's areas $12,32,44,45,46,8,6, M 1$, and $S 1$ on the left side and the cingulate gyrus on the right side.

even though he understood verbal commands he remained mute (mutism after a bilateral frontal lesion ${ }^{7}$ ) until his death in July 1995.

NEUROPSYCHOLOGICAL EVALUATION

On 16 and 17 January 1995, three and a half months after his first operation, the patient underwent a neuropsychological and neurolinguistic assessment. On repeated neurological examination he only exhibited a slight dragging of the right lower limb when walking. During the neuropsychological and neurolinguistic assessment the patient was often euphoric and sometimes verbally disinhibited. He did not make any error on the Raven coloured progressive matrices (36/36) nor in the tests aimed at assessing attention (three tests of visual searching for one, two, or three target numbers in a matrix were completed in less than 45 seconds and without errors; the performance of age and education matched controls was 50.4 (SD 8.8) seconds $^{8}$ ). The patient scored 16 in a long term verbal memory test (story telling), whereas age and education matched non-brain damaged controls scored 12.4 (SD 3.7). ${ }^{8}$ In the forward digit span subtest of the Wechsler's scale the patient scored 9 and age and education matched non-

Scores at the bilingual aphasia test and pathological switching

\begin{tabular}{llll}
\hline Linguistic skills & L1 & L2 & \\
\hline Comprehension & $143 / 149$ & $147 / 149$ & \\
Repetition & $67 / 67$ & $67 / 67$ & \\
Judgment & $29 / 30$ & $30 / 30$ & \\
Lexical access & $60 / 60$ & $60 / 60$ & \\
Propositionising & $15 / 15$ & $15 / 15$ & \\
Reading & $56 / 56$ & $56 / 56$ & \\
Writing & $20 / 20$ & $20 / 20$ & \\
Grammaticality judgement & $14 / 14$ & $13 / 14$ & \\
Translation tasks & $\mathrm{L} 1 \rightarrow \mathrm{L} 2$ & $\mathrm{~L} 2 \rightarrow \mathrm{L} 1$ & \\
$\quad$ Translation of words & $14 / 15$ & $15 / 15$ & \\
$\quad$ Translation of sentences & $5 / 6$ & $5 / 6$ & By the examiner \\
Utterances produced & By the patient & $\mathrm{L} 2$ & $\mathrm{~L} 1$ \\
& $\mathrm{~L} 1$ & 122 & $\mathrm{~L} 2$ \\
Appropriate language & 102 & 94 & - \\
Switching & 71 & - & - \\
Mixing & 2 & & - \\
\hline
\end{tabular}

L1=language $1 ;$ L2=language 2. brain damaged controls scored on average 6.2 (SD 1.4). He performed almost perfectly in tests assessing ideomotor and constructional praxic abilities. ${ }^{8}$ In summary, neuropsychological tests indicated that the patient did not present neither intellectual nor attentional or praxic disorders, whereas he displayed disorders peculiar to patients with frontal lesions such as verbal disinhibition, reduction of anxiety, and a tendency to tell dirty jokes. ${ }^{9}$

\section{NEUROLINGUISTIC EVALUATION}

The neurolinguistic assessment of the patient's two languages was carried out on two separate days. The first language of the patient was Friulian, a Rhaeto-Romance language spoken by over half a million people in north eastern Italy in areas bordering on Austria and Slovenia. The structural distance between Friulian and Italian may be roughly compared to the one between Catalan and Spanish. ${ }^{10}$ On the first day the examiner (FF) addressed the patient in Italian only. Each time the patient switched to Friulian he was reminded that he had to speak only in Italian. He was administered the short version of the Italian adaptation of the bilingual aphasia test (BAT) ${ }^{11}$ On the second day the patient's competence in Friulian was assessed by using the short version of the BAT (Friulian adaptation). ${ }^{12}$ During this test the examiner only used Friulian and each time the patient switched to Italian he was reminded that he had to speak only in that language. Friulian-Italian translation tests were also administered on the second day. Neurolinguistic tests performed in both $\mathrm{L} 1$ and $\mathrm{L} 2$ show that the patient did not exhibit aphasic symptoms in any of the two languages tested, nor did he make translation errors in any of the two directions (table).

\section{Results}

The most relevant feature of the patient's pathological verbal behaviour is that he did not mix languages within one utterance (mixing 
phenomenon) showing instead pathological switching - that is, the compulsive tendency to alternate utterances in Italian and utterances in Friulian. He was aware that he had to speak in only one language; but he switched to the other even though he often commented on, or apologised for it immediately after doing so. When requested to speak in $\mathrm{L} 1$, the patient produced $58.3 \%$ of the utterances in that language, $40.6 \%$ in the unwanted L2, and only $1.1 \%$ of mixed utterances. When requested to speak in L2, the patient produced $56.5 \%$ of utterances in L2 and $43.5 \%$ of utterances in L1. No utterances with elements of the two languages were recorded in this session. No interference between languages was found by the examiner (table).

The pattern of pathological switching was present even when the patient addressed people who could not understand one of the two languages. For instance, he used Friulian to address the hospital staff in Trieste who did not understand this language. In normal conversation settings, Friulan-Italian bilingual subjects avoid code switching between the two languages for sociolinguistic reasons. Moreover, during conversation in L2 he changed register 13 times (six times while producing utterances in L2 and seven in L1). During conversation in L1 changes in register were recorded three times, always during utterances in L1. These changes in register mainly consisted of dirty jokes. On two occasions the patient was so aware of this behaviour that he apologised for it.

\section{Discussion}

Non-brain damaged bilingual subjects can separate their languages at will and use each language in appropriate contexts. They can intentionally combine elements of the different languages within an utterance (mixing) or across utterances (switching). They may also produce unwanted mixing or switching in context driven situations, such as conversations in which different languages are used. It is worth noting, however, that non-brain damaged bilingual subjects hardly ever violate the sociolinguistic rule taking into account whether or not the used languages are understood by their interlocutors. ${ }^{13}$

Many neurologists in the past postulated the existence of a parietal centre responsible for the ability to use a given language at will. ${ }^{12}{ }^{14} 15$ Subsequent studies have distinguished pathological switching and pathological mixing phenomena. ${ }^{34}$ Additional studies have established that pathological mixing is mainly due to lesions in the parietotemporal structures of the left hemisphere, whereas the nervous structures responsible for switching between languages have not been clearly described so far. ${ }^{56}$ A recent functional imaging study has shown an increased activation of the left inferior frontal region and bilateral supramarginal gyri during switching tasks between words in German and English in normal bilingual subjects. ${ }^{16}$ However, the fact that frontal lobes may regu- late the use of different languages in bilingual subjects has been posited only on theoretical grounds. ${ }^{17}$ By using a systematic linguistic analysis, we have provided evidence - for the first time in a bilingual brain damaged subject-for the important part played by anterior cingulate, prefrontal, and frontal structures in switching between languages. Moreover, this result remarkably implies that utterance segmentation is not a mere linguistic concept but has a neurological basis. As already maintained by Hughlings Jackson last century, not only words but also utterances are represented in the brain as linguistic units. ${ }^{18}$

Another important question is whether the decision to speak in one language rather than in another is regulated by a specific cognitive system peculiar to bilingual subjects or by a general system responsible for switching between various behavioural patterns. Decisions to switch from a given behaviour to another (for example, from sitting to walking), or from one linguistic register to another, or even from one language to another may all be regulated by the same general neural mechanism, ${ }^{19}$ which may be neurofunctionally separate and independent of the linguistic system and of the translation system. ${ }^{5}$ The lack of aphasic symptoms in the patient reported here suggests that the system responsible for switching between languages is independent of language, being part of a more general system underlying the selection of different behaviours.

1 Pötzl O. Aphasie und Mehrsprachigkeit. Zeitschrift für die gesamte Neurologie und Psychiatrie 1930;12:145-62.

2 Leischner, A. Über die Aphasie der Mehrsprachigen. Archiv für Psychiatrie und Nervenkrankheiten 1948;180:731-75.

3 Paradis M. Bilingualism and aphasia. In: Whitaker $\mathrm{H}$, Whitaker HA, eds. Studies in neurolinguistics. New York: Academic Press, 1977;3:65-121.

4 Albert ML, Obler LK. The bilingual brain. New York: Academic Press, 1979.

5 Fabbro F. The neurolinguistics of bilingualism. Hove: Psychology Press, 1999

6 Fabbro F. Aphasia in multilinguals. In: Fabbro F, ed. Concise encyclopedia of language pathology. Oxford: Pergamon Press, 1999:335-41.

7 Jürgens U, Von Carmon D. On the role of the anterior cingulate cortex in phonation: a case report. Brain Lang 1982; 15:234-48.

8 Spinnler H, Tognoni G, eds. Standardizzazione e taratura italiana di test neuropsicologici. Ital 7 Neurol Sci 1987; taliana di test

9 Grafman J. Alternative frameworks for the conceptualization of prefrontal lobe functions. In Boller F, Grafman J. Handbook of neuropsychology. Amsterdam: Elsevier, 1994;9: 187-201.

10 Haiman J, Benincà P. The rhaeto-romance languages. London: Routledge, 1992.

11 Paradis M. The assessment of bilingual aphasia. Hillsdale, NJ: Erlbaum, 1987.

12 Paradis M, Fabbro F. Bilingual aphasia test. Friulian version. Hillsdale, NJ: Erlbaum,1993.

13 Grosjean F. Studying bilinguals: methodological and conceptual issues. Bilingualism Language and Cognition, 1998;1:131-40.

14 Lebrun Y. Polyglotte Reaktionen. Neurolinguistik 1991;5:19.

15 Schwartz M. Ictal language shift in a polyglot. If Neurol Neurosurg Psychiatry 1994;57:121.

16 Price CJ, Green DW, von Studnitz R. A functional imaging study of translation and language switching. Brain 1999; 122:2221-35

17 Zatorre RJ. On the representation of multiple languages in the brain: old problems and new directions. Brain Lang 1989;36:127-47.

18 Jackson JH. On the nature of the duality of the brain. In: Taylor J, ed. Selected writings of fohn Hughlings fackson. New York: Basic Books, 1958:129-145. (Original work published 1874.)

19 Paradis M, ed. Aspects of bilingual aphasia. Oxford: Pergamon Press, 1995. 